\title{
Exposição infantil à publicidade em sites de jogos do Brasil e da Espanha
}

Children's exposure to advertising on games sites in Brazil and Spain

\author{
Pâmela Saunders Uchôa Craveiro ${ }^{1}$ \\ Daniel Martí Pellón ${ }^{2}$
}

Resumo $O$ presente artigo tem como objetivo confirmar dados gerais sobre a pressão publicitária que afeta as crianças ao brincarem em páginas de jogos na internet. Para alcançar tal objetivo, aplicamos os referenciais teórico-metodológicos da análise de conteúdo em uma amostra de sites de jogos acessados por um grupo de crianças do Brasil e da Espanha.

Palavras-chave: Publicidade; Internet; Criança; Análise de Conteúdo

\begin{abstract}
This article aims to confirm general data about the advertising pressure that affects children that play on game pages on the Internet. To achieve this goal, we applied theoretical and methodological framework of content analysis on a sample of games sites played by a group of children in Brazil and Spain.
\end{abstract}

Keywords: Advertising; Internet; Children; Content Analysis

\footnotetext{
${ }^{1}$ Universidade Federal do Ceará - UFC, Fortaleza, CE, Brasil.

E-mail: pamela_uchoa@yahoo.com.br

${ }^{2}$ Universidade de Vigo - UVIGO, Vigo, Pontevedra, Espanha.

Email:dmarti@uvigo.es
} 


\section{Introdução}

Considerando a influência dos meios de comunicação de massa e das tecnologias informáticas nas transformações ocorridas no brincar das crianças nas últimas décadas, faz-se necessário entender a cultura lúdica infantil no contexto atual das mídias eletrônicas e digitais. Entre os vários elementos que compõem a cultura lúdica contemporânea, destaca-se o fenômeno dos jogos eletrônicos (JE's) como tendência relevante para o ato de brincar, fruto do momento histórico e cultural em que as crianças atuais estão inseridas.

Os avanços tecnológicos, as novas rotinas da sociedade e o aumento da violência urbana - que tem reduzido o acesso das crianças aos espaços públicos de brincadeiras - são alguns fatores que contribuem para fazer com que a atual cultura do brincar infantil sofra modificações. Nesse contexto de mudanças, os JE's tornaram-se uma forma de entretenimento habitual entre as crianças, e a internet converteu-se em uma importante ferramenta dessa geração. Estudos a nível macro confirmam essa penetração das novas tecnologias e dos JE’s nas práticas de crianças norte-americanas (KAISER FAMILY FOUNDATION, 2010), europeias (EU KIDS ONLINE, 2010) e brasileiras (TIC KIDS ONLINE, 2013).

Entre os vários suportes e possibilidades existentes para se jogar JE's, este artigo foca nos jogos hospedados em servidores de internet. A escolha por estudar os jogos na internet justifica-se pelo fato de que a rede mundial de computadores tem funcionado como um território cada vez mais ocupado pelas crianças. Navegar na web tem incutido um sentimento de liberdade nos mais jovens que se contrapõe ao controle tradicional mantido pela família e pela escola.

Se por um lado, os JE's são ferramentas lúdicas com que as crianças brincam, por outro lado, não se pode deixar de considerar que, com o crescente número de usuários e a movimentação de bilhões de dólares por ano, além de atividade lúdica cada vez mais presente no cotidiano das crianças, os JE's tornaram-se também excelentes ferramentas publicitárias. 
Somente como plataformas publicitárias, os JE’s, em 2009, acumularam 823 milhões de dólares nos Estados Unidos (PURO MARKETING, 2010). No Brasil, a combinação de jogo e publicidade denominada advergame alcançou, em 2011, 3 bilhões de dólares (CAMPI, 2012). Em 2012, na Espanha, foram gastos em jogos promocionais 27,9 milhões de euros (INFOADEX, 2013).

Nesse contexto de uma infância permeada pelos meios de comunicação e pelas novas tecnologias, a proteção da infância emerge como um assunto pendente e se constitui em um tema especialmente sensível e complexo. A preocupação em impulsionar os direitos da criança nos meios de comunicação e nas novas tecnologias é um fenômeno mundial recente que tem avançado mais rapidamente em algumas regiões e menos em outras.

Os meios de comunicação juntamente com a ação dos governos e das demais instituições - como escola, família, igreja etc. - exercem um papel fundamental na promoção e difusão da cultura em nossa sociedade. A publicidade, especificamente, é uma das formas mais recorrentes de comunicação e por isso não deve ser ignorada. Nosso cotidiano é invadido por muitos anúncios que, ao vender produtos e serviços, contribuem para a delimitação dos valores que configuram nossa cultura (ÁNGELES, 2001).

Justamente pela publicidade se tratar de uma atividade crescente em importância e influência, muitas são as iniciativas empreendidas para a proteção da infância sobre seus efeitos. No Brasil e na Espanha ainda não há uma regulamentação específica para a publicidade direcionada às crianças. Muitas entidades debatem sobre o tema e lutam por uma regulamentação da publicidade infantil nesses países.

Nesse panorama, parece oportuno não esperar a legislação ou as estratégias comerciais da indústria do entretenimento para conhecer em primeira mão o conteúdo publicitário de alguns sites de jogos acessados por crianças brasileiras e espanholas. 
A globalização e a difusão dos usos tecnológicos e de práticas de consumo divulgam os jogos de sucesso por qualquer país do mundo. Universos mestiços e perfis padrões são propostos pelos meios de comunicação e por empresas continuadoras das indústrias culturais nos setores de jogos. Por este motivo, propõe-se um estudo que enfoca a publicidade em jogos a partir de sites espanhóis e brasileiros. Com a análise do conteúdo da publicidade exibida em sites de jogos de duas culturas distintas, pretende-se buscar comparações e diferenças das óticas transoceânicas brasileiras e espanholas.

O objetivo, portanto, da análise da publicidade exibida em páginas de jogos na internet, que se delineará neste artigo, é confirmar dados gerais sobre a pressão publicitária que afeta crianças do Brasil e da Espanha ao brincarem on-line. Esses dados a serem confirmados dizem respeito à análise de entrevistas realizadas, em estudo anterior (CRAVEIRO e RIOS, 2013), com crianças brasileiras e espanholas de 9 a 11 anos. Para alcançarmos tal objetivo, aplicamos os referenciais teórico-metodológicos da análise de conteúdo em uma amostra de sites de jogos acessados por esse mesmo grupo de crianças anteriormente estudado.

\section{Parâmetros, características e formatos da publicidade em sites infantis de jogos}

As tecnologias têm expandido o acesso à informação e, com a portabilidade e a mobilidade, multiplicam-se as possibilidades de comunicação com mais pessoas, em vários formatos e, praticamente, de qualquer lugar. Crescem também as possibilidades de interação. Assuntos que somente eram notícia na mídia tradicional, agora resultam em opiniões, comentários, curtidas ou trending topic nas redes sociais da internet.

Os JE's fazem parte desse fenômeno tecnocultural recente. São oriundos do surgimento e desenvolvimento dos mecanismos informáticos, da transformação do computador em aparato de comunicação e da convergência das mídias. Popularizaram-se na década de 1980 e, nos 
anos 1990, devido ao seu impacto social e ao volume de vendas alcançado, assumiram status de artefatos culturais de grande relevância.

A publicidade também sofreu mudanças. Como aponta Méndiz (2010), nos últimos anos, tem sido evidenciada a implantação de um esquema interativo no processo publicitário que desenvolveu mudanças profundas no paradigma comunicativo. Esse novo marco interativo transformou radicalmente os três pontos fundamentais do conceito de publicidade que durante muito tempo caracterizou-se por apresentar uma comunicação unidirecional, separação entre informação e publicidade, e intencionalidade persuasiva. No novo paradigma publicitário, esses três pontos foram questionados e as mensagens passaram a caracterizar-se, principalmente, por apresentarem uma comunicação bidirecional, hibridação entre publicidade e informação, e experiência lúdica.

O relevante no paradigma anterior era a valorização da presença da marca. Em contrapartida, na atualidade, tem sido mais valorizada a experiência lúdica do consumidor. Mais do que buscar informação sobre o produto, o consumidor deseja identificar-se e viver uma experiência gratificante com a marca anunciada. É nesse contexto de mudança de paradigma na comunicação publicitária que se consolida o formato publicitário advergame, um neologismo inglês formado a partir da junção de advertising (publicidade) e videogame (videojogos). Esse jogo com pretensão publicitária, juntamente com o patrocínio e a publicidade contextual, destaca-se sobre os formatos tradicionais da época dourada da televisão.

O advergame diferencia-se do product placement que é outra opção oferecida às marcas que anunciam nos JE's já bastante utilizada em filmes e programas televisivos. Ainda que ambos os conceitos se caracterizem pela utilização dos JE's como meio de difusão de mensagens publicitárias, no advergame, o jogo é desenvolvido de acordo com as necessidades de comunicação de uma marca específica e tem o objetivo de criar uma experiência lúdica com o possível consumidor, enquanto no product placement, o jogo é desenvolvido independentemente da ação de comunicação das marcas que são inseridas neles após serem criados 
(MARTÍ e CURRÁS, 2012). Méndiz (2010) denomina o product placement aplicado nos jogos eletrônicos de in-game advertising.

Outro tipo de publicidade presente nos JE's é aquela inserida nos mundos virtuais, considerada um tipo de advergame e denominada por Méndiz (2010) de virtual world advertising. A inserção de marcas e produtos reais nos mundos virtuais contribuem para realçar o realismo do entorno desses sites.

Para Martí (2010), a vantagem da associação entre publicidade e JE's está no fato de que, em meio a uma saturação dos suportes publicitários tradicionais, os JE's possuem um importante valor de entretenimento que serve como gancho para atrair consumidores cansados de uma publicidade que eles não hesitam em eliminar quando são inoportunas.

González, Francés (2009); Méndiz (2010) e trabalhos posteriores destacam que o advergame pode ser uma excelente ferramenta para os anunciantes que desejam direcionar sua comunicação para o público infantil. Diferentemente dos formatos convencionais de publicidade que fomentam uma relação mais passiva e, muitas vezes, pouco atrativa para as crianças, o advergame coloca o público infantil em contato direto com a marca e possibilita uma interação maior. Ademais, pelo fato de as crianças em geral possuírem o hábito de jogar frequentemente, elas já conhecem a linguagem dos JE's e, dessa forma, podem desenvolver mais facilmente uma afinidade e identificação com as marcas divulgadas nos jogos. Além disso, uma vez que as crianças ainda estão entrando no mundo do consumo, os JE's podem ser utilizados pelos anunciantes como um importante instrumento de fidelização e até mesmo de educação para o consumo.

As empresas, portanto, que desejam atingir o público infantil por meio de publicidade nos sites de jogos podem recorrer às seguintes estratégias, já conceituadas anteriormente, de associar publicidade e JE's:

- Advergame;

- In-game advertising;

- Virtual world advertising. 
As empresas podem ainda recorrer aos diversos formatos de publicidade on-line existentes no mercado ${ }^{3}$ como:

- Background: compõe o plano de fundo do site;

- Banner: espaço horizontal com conteúdo estático ou não;

- Botão: formato retangular com espaço para exibição da marca do anunciante;

- Classificados: enunciados similares aos dos jornais impressos, listados por categoria de produto;

- Intersticial: exibido entre páginas num site, geralmente, possui um tempo determinado para fechar;

- Patrocínio: associação entre uma marca e um site com o intuito de relacionar o conteúdo oferecido ao patrocinador;

- Pop-under: janela que surge em segundo plano;

- Pop-up: janela que surge em primeiro plano, tapando o conteúdo que se estava acessando;

- Skyscraper: similar ao banner, porém com disposição vertical, possui a vantagem de não desaparecer com a navegação vertical (scroll) do usuário;

- Slotting fee: veiculado em local determinado (topo, meio do texto, centro da página), com formatos diversificados;

- Subset: assim como o skyscraper, aparece verticalmente na página, porém, a sua altura é menor, fazendo com que o anúncio desapareça com a navegação vertical (scroll) do usuário;

- Supersticial: surge sobre o conteúdo do site por um tempo determinado. Diferentemente do pop-up, surge em uma layer acima do conteúdo da página e não em uma janela em separado.

Nesse contexto de variadas estratégias de divulgação publicitária em jogos na internet, entendemos ser relevante estudar o conteúdo da publicidade destinada aos pequenos consumidores de jogos on-line, de modo que possamos medir e avaliar a pressão publicitária a que estão expostos.

\footnotetext{
${ }^{3}$ As definições dos tipos de anúncios foram baseadas nos trabalhos de Brandão e Moraes (2004), Carniello e Assis (2009), Nordeste (2009) e Sebastião (2011).
} 


\section{Procedimentos metodológicos}

Este artigo analisa os conteúdos publicitários exibidos em sites de jogos acessados por 20 crianças brasileiras e 29 espanholas, com nove a 11 anos, anteriormente observadas e entrevistadas (CRAVEIRO e RIOS, 2013). Nesse estudo anterior, foram realizadas entrevistas semiestruturadas (TRIVIÑOS, 1987) que aconteceram enquanto as crianças brincavam em seus sites de jogos favoritos nas salas de computadores de suas escolas. Nessa fase prévia de entrevistas, concluiu-se que, de modo geral, as crianças estudadas de ambos os países ficam incomodadas com a publicidade veiculada nos sites de jogos, pois, segundo elas, é demasiada, desinteressante e irritante, pois surge no meio da tela, atrapalhando o jogo.

Após o processo de escuta de seus comentários, objeções e propostas acerca dos anúncios visualizados enquanto jogavam on-line, pretendeu-se, neste trabalho que aqui se delineia, confirmar o que disseram as crianças nas entrevistas e, assim, conhecer o tipo e a quantidade de publicidade que efetivamente as impacta durante uma experiência de jogar na sala de informática de suas escolas durante uma hora livre.

As crianças espanholas acessaram 11 sites diferentes e as brasileiras, nove. Entre esses sites, há mundos virtuais, redes sociais, portais e páginas que contêm apenas um único jogo. Eliminamos da análise os sites acessados por apenas uma criança. Desse modo, as páginas de jogos analisadas foram as seguintes:

- Do Brasil:

○ www.clickjogos.uol.com.br

○ www.iguinho.ig.com.br

○ http://www.stardoll.com/br/

○ www.obaid.com.br

○ www.clubpenguin.com

- Da Espanha:

○ www.juegosdechicas.com/

$\circ$ www.juegosjuegos.com/

○ www.habbo.es 
○ es.akinator.com/

○ www.ciudadpixel.com.es

○ www.clubpenguin.com

Recorremos aos instrumentais metodológicos da análise de conteúdo a partir das proposições de Bardin (2004); Bauer, Gaskell e Allum (2004); Fonseca Júnior (2010); Piñuel Raigada (2002). Entre as técnicas possíveis de serem aplicadas, segundo a análise de conteúdo, utilizamos a análise de frequência, que consiste na contagem da frequência de determinadas características codificadas do material analisado.

As técnicas foram selecionadas para quantificar a presença, as formas de apresentação e a frequência, de acordo com o objetivo do presente estudo, que foi triangulado desde os dados observados a partir das opiniões infantis para, em seguida, completar-se agora com a programação publicitária dos anunciantes em sites de jogos na internet.

Os seguintes aspectos foram considerados na análise:

a. A origem da distribuição da publicidade: se veiculada pelo site ou como veiculação contextualizada (patrocinada) pelo site Google durante a navegação.

b. A posição e ocupação dos anúncios na tela: se estavam localizados na parte superior, inferior, no meio, nas laterais, por cima ou por trás da tela.

c. O tipo de formato dos anúncios, identificados segundo a denominação profissional publicitária indicada na seção anterior deste artigo.

d. O caráter global ou nacional das marcas anunciadas.

e. O nível de interação que os anúncios permitem ou solicitam do usuário: baixo (apenas visualização do anúncio), médio (um clique, passar para outra página, ver um vídeo etc.) ou alto (envolve o consumidor em uma experiência com a marca).

f. A natureza generalista ou segmentada dos anúncios. 


\section{A publicidade nos sites de jogos brasileiros e espanhóis}

A análise permitiu que traçássemos um panorama da publicidade veiculada nos sites de jogos acessados por crianças do Brasil e da Espanha, mostrando que os espaços lúdicos de jogos on-line são permeados por um grande contingente de publicidade. O campo concreto de anúncios analisados é composto de 158 anúncios nos sites espanhóis e 126 nos sites brasileiros.

Como mostra os resultado no Gráfico l, é superior a publicidade própria dos sites brasileiros, enquanto no sites de jogos espanhóis há mais publicidade contextualizada pelo Google nas navegações dos usuários.

anúncios do próprio site

-Anúncios Google

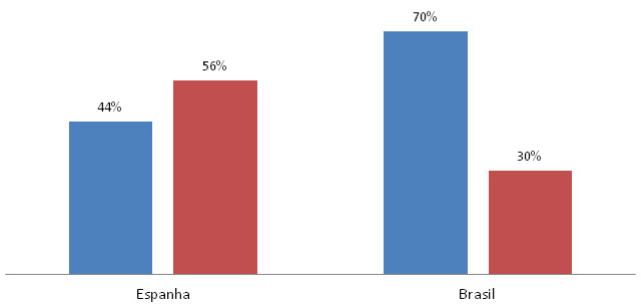

Gráfico 1: Distribuição dos anúncios Fonte: Elaborado pelos próprios autores.

A análise dos dados revela maior número de anúncios e certo grau de personalização na navegação infantil de espanhóis superiores aos dos brasileiros. A menor presença de publicidade em sites de jogos do Brasil conta com a vantagem de supor acessos diretamente geridos e cobrados por eles mesmos e não dependentes da mediação do Google.

Sobre a posição e a ocupação dos anúncios analisados, comprova-se nos gráficos 2 e 3 que a ocupação central da tela é a tática publicitária predominante, forçando a uma inevitável recepção infantil do anúncio tanto nos sites brasileiros quanto nos espanhóis. A mostra de publicidade na lateral da tela é claramente menor. Desse modo, os anúncios acabam 
prejudicando a navegação e a visualização do conteúdo das páginas web, o que justifica as críticas das crianças à publicidade nesse tipo de site. ${ }^{4}$

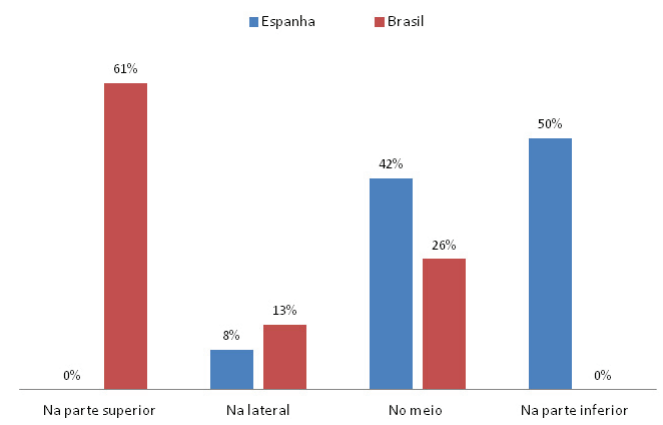

Gráfico 2: Disposição dos anúncios Google na tela

Fonte: Elaborado pelos próprios autores.

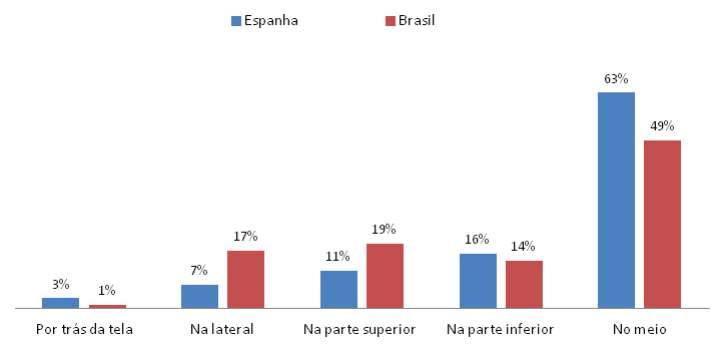

Gráfico 3: Disposição dos anúncios dos próprios sites na tela Fonte: Elaborado pelos próprios autores.

Com relação ao formato dos anúncios, entre aqueles contextualizados pelo Google, dominam os menos intrusivos como o banner $(55 \%$ nos sites brasileiros e 50\% nos sites espanhóis), o slotting fee (29\% nas páginas brasileiras e $25 \%$ nas espanholas) e o subset que somente consta com mais expressividade nos sites da Espanha (25\%). Como mostra a tabela a seguir, os formatos que as crianças consideram mais incômodos

\footnotetext{
${ }^{4}$ As opiniões das crianças brasileiras e espanholas sobre a publicidade nos jogos on-line constam no artigo publicado em Estudios sobre el Mensaje Periodístico, disponível em: <http://revistas.ucm.es/ index.php/ESMP/article/view/42136/40115>
} 
(pop-up, supersticial e intersticial), ${ }^{5}$ porque surgem no meio da tela e atrapalham o jogo, não aparecem entre os anúncios patrocinados por meio do Google.

\begin{tabular}{|l|c|c|}
\hline $\begin{array}{c}\text { TIPOS DE } \\
\text { ANÚNCIOS }\end{array}$ & BRASI & ESPANHA \\
\hline Banner & $55 \%$ & $50 \%$ \\
\hline Classificados & $13 \%$ & $0 \%$ \\
\hline Slotting fee & $29 \%$ & $25 \%$ \\
\hline Subset & $3 \%$ & $25 \%$ \\
\hline
\end{tabular}

Tabela 1: Tipos de anúncios Google Fonte: Elaborada pelos próprios autores.

A tabela seguinte mostra que entre os formatos veiculados pelos próprios sites de jogos, aparecem tanto formatos intrusivos quanto os considerados menos incômodos pelas crianças participantes do estudo. Somando-se os formatos pop-under, intersticial e supersticial, tem-se 24\% de anúncios intrusivos em sites espanhóis e nos brasileiros chega a ser $19 \%$ dos anúncios exibidos. Pode-se concluir, a partir desses dados, que somente a metade dos anúncios é veiculada em formatos que atrasam e/ou atrapalham a visualização do jogo.

\begin{tabular}{|l|c|c|}
\hline $\begin{array}{c}\text { TIPOS DE } \\
\text { ANÚNCIOS }\end{array}$ & BRASIL & ESPANHA \\
\hline Adverga me & $1 \%$ & $0 \%$ \\
\hline Background & $8 \%$ & $1 \%$ \\
\hline Banner & $35 \%$ & $10 \%$ \\
\hline Botão & $9 \%$ & $12 \%$ \\
\hline Inter sticial & $4 \%$ & $0 \%$ \\
\hline Patrocinio & $0 \%$ & $4 \%$ \\
\hline Pop-under & $1 \%$ & $3 \%$ \\
\hline Pop-up & $0 \%$ & $0 \%$ \\
\hline Sl otting fee & $26 \%$ & $26 \%$ \\
\hline Subset & $1 \%$ & $1 \%$ \\
\hline Supersticial & $15 \%$ & $24 \%$ \\
\hline $\begin{array}{l}\text { Virtual World } \\
\text { Advertising }\end{array}$ & $0 \%$ & $19 \%$ \\
\hline
\end{tabular}

Tabela 2: Tipos de anúncios dos próprios sites Fonte: Elaborada pelos próprios autores.

${ }^{5}$ Formatos definidos anteriormente neste artigo, no tópico "Parâmetros, características e formatos da publicidade em sites infantis de jogos". 
Ao observarmos as duas tabelas apresentadas acima, podemos perceber que o advergame foi muito pouco utilizado nos sites de jogos brasileiros e não utilizado nos sites espanhóis.

A Figura 1 mostra um exemplo de advergame exibido no portal Click Jogos, como uma publicidade do suco Ades que possibilita ao usuário vivenciar uma experiência com a marca por meio de um jogo em que o consumidor é convidado a superar alguns desafios para resgatar uma caixa de suco. A marca Ades, ao usar o formato advergame, desenvolveu uma peça publicitária que possibilita maior interação, utilizando-se da afinidade das crianças com os JE's e, assim, desenvolvendo uma identificação maior com o público infantil.
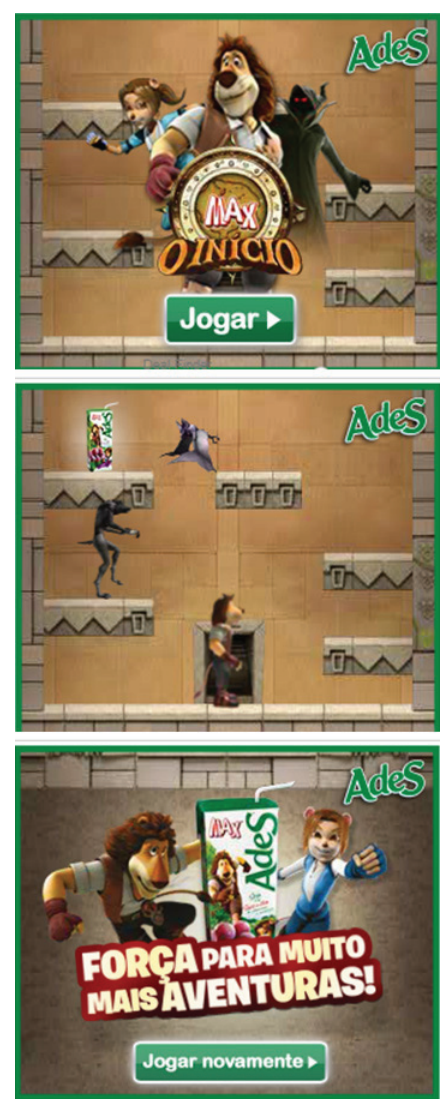

Figura 1: Exemplo de advergame

Fonte: www.clickjogos.com.br/ 
Também merece atenção o fato de não se usar o formato virtual world advertising nos sites de jogos do Brasil e ter apenas um quinto de presença nos sites da Espanha, sendo superado apenas pelos formatos supersticial e slotting fee.

Um exemplo de virtual world advertising é a publicidade da rede social Facebook veiculada no mundo virtual Ciudad Pixel. Como pode ser visto na Figura 2, uma sala inteira do site foi decorada com vários objetos com a logo do Facebook, contribuindo para tornar esse espaço mais próximo da realidade e permitindo que os usuários tenham uma experiência com a marca.

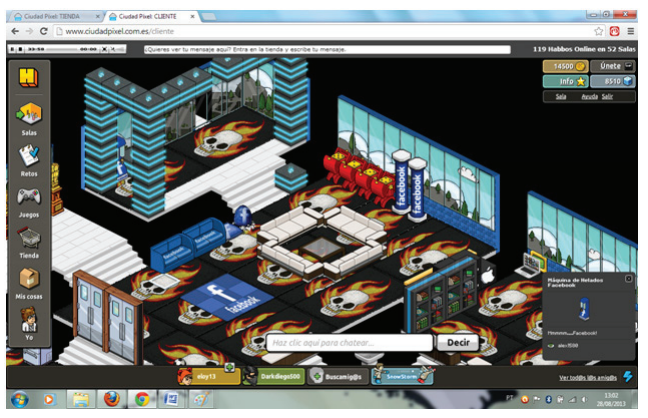

Figura 2: Exemplo de virtual world advertising Fonte: www.ciudadpixel.org

Tanto o advergame como o virtual world advertising são formatos mais adequados ao atual paradigma publicitário com tendência a oferecer ao consumidor uma experiência lúdica com a marca. Sua ausência nos espaços de jogos na internet deixa de aproveitar as afinidades que voluntariamente os pequenos jogadores podem ter com esses formatos.

Quanto à natureza da publicidade analisada, como se pode ver nos dados apresentados no Gráfico 4, é surpreendente que, apesar das possibilidades de segmentação que oferecem os jogos, a maioria dos anúncios, tanto na programação brasileira (74\%) quanto na espanhola (54\%), seja genérica e não esteja direcionada ao público infantil que joga nesses sites. 


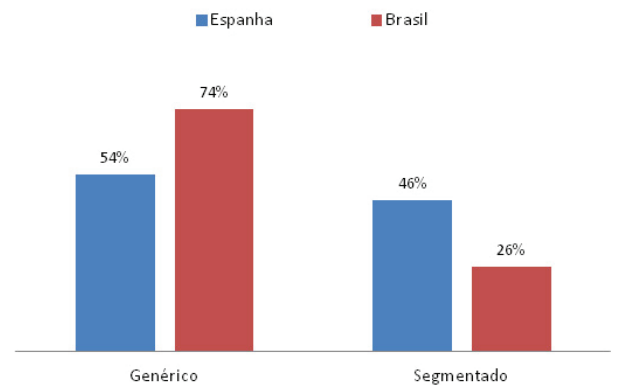

Gráfico 4: Natureza dos anúncios

Fonte: elaborado pelos próprios autores.

O anúncio do tipo virtual world advertising do salgadinho Cheetos da marca Elma Chips, veiculado no mundo virtual Habbo, é um exemplo de publicidade segmentada para o público infantil. Duas máquinas de autovendas foram adicionadas a salas do mundo virtual (Figura 3), simulando a venda do produto. Esse anúncio segue a mesma linha de comunicação do produto Cheetos realizada em outros meios de comunicação, utilizando a imagem lúdica da mascote guepardo Chester Cheetah (Figura 4). O uso dessa mascote torna a comunicação com o público infantil mais emotiva, lúdica e atrativa.

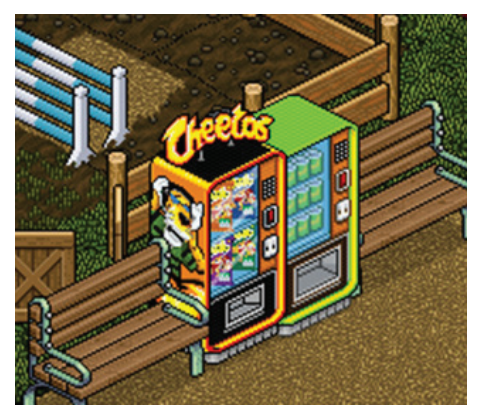

Figura 3: Anúncio da marca Elma Chips

Fonte: www.habbo.es

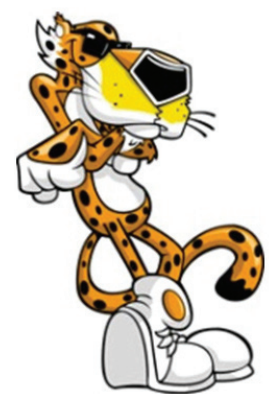

Figura 4: Mascote Chester Cheetah

Fonte: www. brainstormbreakfast.wordpress.com 
Outro fator que pode influenciar a percepção dos usuários sobre a atratividade dos anúncios é o nível de interação proposto nas mensagens publicitárias. Os anúncios de nível alto de interação tornam-se mais atrativos que os de nível médio e baixo, pois envolvem os consumidores em alguma atividade promocional que vai além do próprio anúncio ou em alguma experiência com a marca e/ou produto anunciado.

Um nível mais alto de interação apresenta o anúncio exibido anteriormente na Figura 4 e também o banner dinâmico do picolé Calippo da marca Frigo (Figura 5), veiculado no site Juegos de Chicas. Ademais da visualização da mensagem publicitária, neste anúncio, o usuário é intimado a compartilhar suas experiências com o produto por meio da participação em uma promoção que irá premiar os vencedores com um tablet.

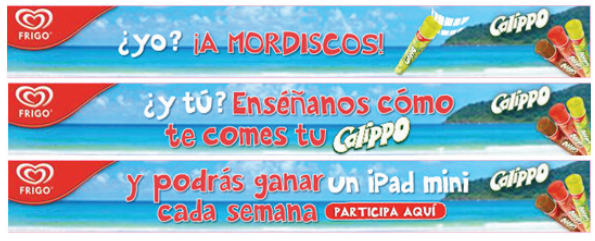

Figura 5: Banner dinâmico

Fonte: www.juegosdechicas.com

O Gráfico 5 mostra que os anúncios de alta interatividade ainda não são maioria nos sites de jogos de ambos os países estudados.

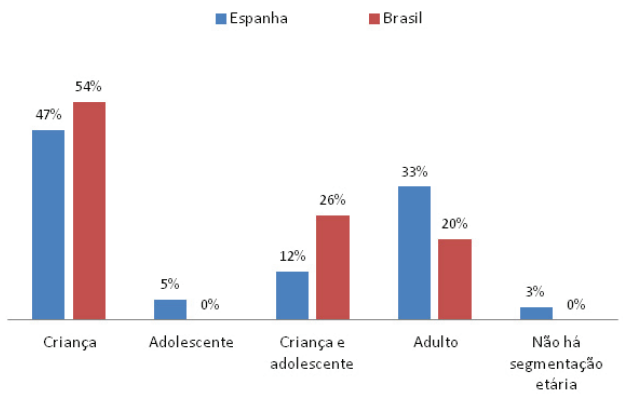

Gráfico 5: Nível de interação dos anúncios

Fonte: Elaborado pelos próprios autores. 
É muita ampla a publicidade multinacional durante o tempo de jogo das crianças participantes do estudo. Como indica o Gráfico 6, somente $4 \%$ das marcas anunciadas no período de análise eram espanholas e $11 \%$ eram de empresas brasileiras. Apesar desse domínio da publicidade internacional nos jogos infantis on-line de ambos os países estudados, nesta amostra, as marcas Disney, Google e Apple foram as únicas que se repetiram na publicidade de ambos os países.

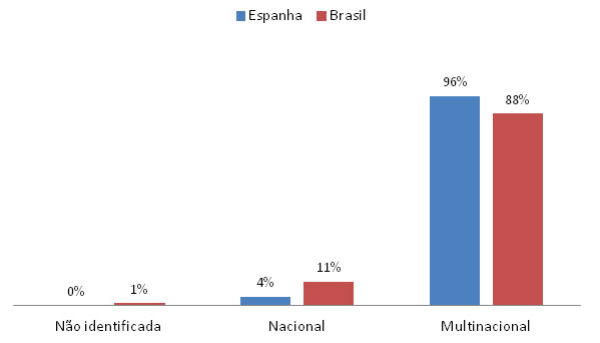

Gráfico 6: Natureza das marcas anunciadas Fonte: Elaborado pelos próprios autores.

Desse modo, confirma-se que os anunciantes multinacionais são os financiadores dos jogos on-line escolhidos por crianças de 9 a 11 anos durante uma experiência de jogo realizada no Brasil e na Espanha.

\section{Conclusões e apontamentos}

O estudo evidenciou que as crianças brasileiras e espanholas participantes da pesquisa, quando brincam on-line nos sites de jogos, estão expostas a uma grande quantidade de publicidade dos mais variados tipos de produtos os quais nem sempre são apropriados para sua idade. Percebe-se nos sites de jogos, portanto, uma saturação publicitária comparável à televisiva.

Desse modo, se existe uma preocupação com a saturação de anúncios televisivos, espera-se que igualmente seja dada atenção aos sites de jogos que repetidamente interrompem e retardam, com apelos comerciais, a experiência do brincar infantil na internet. 
Como foi visto no tópico anterior, os anúncios podem aparecer em qualquer local da tela do site, muitas vezes durante os jogos e até em formatos de jogos (advergames). Essa questão de não haver um local específico e exclusivo destinado aos anúncios nos sites pode ser interpretado como uma estratégia de persuasão do consumidor infantil. Ademais, essas estratégias dos anunciantes podem dificultar a compreensão da intenção persuasiva dos anúncios por parte de algumas crianças, principalmente entre aquelas que não possuem um senso crítico tão apurado sobre os elementos que compõem a publicidade.

Outra consideração a ser feita dos dados apresentados anteriormente é a respeito de as empresas de comunicação que criam anúncios para serem veiculados nos sites de jogos do Brasil e da Espanha não estarem utilizando toda a potencialidade da publicidade on-line. Identificou-se que a maior parte dos anúncios analisados não possibilita um nível de interação alto entre o anunciante e a marca; não utilizam expressivamente formatos que valorizem a experiência lúdica do consumidor com a marca; divulgam mensagens direcionadas para um público genérico e não especificamente para o público infantil. Esses fatores acabam sendo traduzidos na pouca identificação e, consequentemente, rejeição da publicidade por parte de muitos dos consumidores infantis, como foi expresso pelas crianças na fase prévia de entrevistas.

Entretanto, embora se tenha constatado que a publicidade analisada não seja sempre apresentada de uma maneira atrativa para os consumidores infantis, a grande quantidade de anúncios exibidos nos sites facilita que suas mensagens sejam absorvidas pelas crianças e, consequentemente, impacte sua cultura lúdica de jogar on-line.

A análise também evidenciou que nos jogos que compõem especificamente os mundos virtuais, são reproduzidos os estereótipos da sociedade de consumo, ${ }^{6}$ os quais são ativados pelo acúmulo de moeda virtual. A compra de objetos/acessórios, com o uso de moeda virtual, proporciona status aos usuários infantis por meio dos seus avatares. No cenário desse

\footnotetext{
${ }^{6}$ Autores como Baudrillard (1998) e Bauman (2007) defendem que a sociedade pós-moderna é uma sociedade de consumo, em que o indivíduo é visto como consumidor. Nesse modelo de sociedade, o exercício de consumo é algo padronizado que molda as relações dos indivíduos.
} 
tipo de site pode ser mais difícil para as crianças reconhecerem o caráter publicitário de algumas afirmações ou ajudas promocionais disponíveis nos jogos.

Verificou-se ainda que a maioria dos sites espanhóis e brasileiros solicita os dados pessoais dos usuários infantis. O fornecimento desses dados oferece experiências mais ricas de jogos e, além disso, pode possibilitar uma publicidade mais personalizada. Os sites informam se usam ou não os dados dos usuários infantis para direcionar e personalizar publicidade por meio do documento de política de privacidade. Esse documento é apresentado em textos longos e com uso de linguagem técnica, dificultando, dessa forma, o acesso das crianças a essas informações.

\section{Recomendações digitais e a alfabetização para o uso crítico da mídia}

A infância é um período em que as crianças aprendem e conhecem o mundo que as rodeia através do brincar. As brincadeiras podem mudar com o tempo, entretanto, continuam existindo, pois, como declarou Borba (2007), as brincadeiras não são apenas reproduzidas ao longo dos anos, são recriadas a partir do que cada geração traz de novo com seu poder de criar, imaginar e produzir cultura. Desse modo, essa geração de crianças que nasceu na era da internet ganhou um novo espaço onde podem ampliar suas vivências lúdicas. No entanto, devemos nos questionar se a finalidade lúdica de alguns espaços on-line, como os sites de jogos, está sendo priorizada e respeitada.

Sem dúvida, o espaço on-line é rico em experiências lúdicas e pode proporcionar prazeres e aprendizados diversos aos seus usuários mais jovens. Ao jogarem on-line, as crianças têm, inclusive, a oportunidade de compartilhar suas experiências lúdicas com outras crianças sem, necessariamente, estarem em um mesmo espaço físico. Desde que seja respeitada sua finalidade lúdica, o jogo on-line pode ser um espaço de troca de informações de interesse infantil. Entretanto, é bem verdade que nem sempre as crianças podem lidar com o ruído publicitário e 
outros efeitos nocivos derivados de usos excessivos ou inadequados das tecnologias e particularmente dos sites de jogos.

Nesse contexto, defendemos que não são suficientes os sistemas corporativos de autorregulamentação publicitária. O cenário analisado indica que a regulamentação faz-se necessária ao menos para estabelecer alguns limites legais aos anúncios direcionados às crianças. Somando-se a esse panorama, a escola e a família não devem ignorar as práticas infantis on-line, devem funcionar como instituições mediadoras na relação das crianças com a internet, exercendo influência na construção das percepções e dos sentidos dados pelas crianças ao conteúdo presente na rede mundial de computadores.

A mediação dos adultos deve ultrapassar o modelo que se fundamenta na censura do tempo que as crianças passam jogando e/ou do uso do conteúdo publicitário exibido nas páginas web. Segue sendo necessário desenvolver uma alfabetização midiática que estabeleça aceitáveis níveis de competências digitais. Em concreto, é preciso antecipar o conhecimento da intenção persuasiva dos anúncios para que as crianças possam melhor se defender dos argumentos publicitários. Se hoje os anúncios nos sites de jogos não se apresentam de forma tão atrativa ao público infantil, a tendência é que eles se tornem mais interativos e envolventes, sendo assim, as crianças devem estar preparadas para contrapor seus argumentos persuasivos.

Ademais, os anúncios como financiamento do espaço "gratuito" na internet devem ajustar-se ao tempo e às destrezas que demanda cada jogo, para que, assim, a publicidade não se torne um empecilho para a prática de brincar on-line. Uma possível comunicação publicitária de qualidade deve respeitar a criança como um sujeito ativo em processo dinâmico de transformação, mas também como ser em desenvolvimento.

Estimular, portanto, a reflexão crítica infantil sobre os anúncios on-line é contribuir para que as crianças sejam consumidores conscientes dos objetivos comerciais das empresas, bem como dos artifícios de persuasão usados nos anúncios e, consequentemente, sejam consumidores que exigem uma publicidade de qualidade que lhes respeitem como indivíduos. 


\section{REFERÊNCIAS}

ÁNGELES, J. Ética y comunicación persuasiva. In: CODINA, M. De la ética desprotegida: ensayos sobre deontología de la comunicación. Navarra: Ediciones Universidad de Navarra, 2001.

BARDIN, L. Análise de conteúdo. Lisboa: Edições 70, 2004.

BAUDRILLARD, J. A sociedade de consumo. Rio de Janeiro: Elfos, 1998.

BAUER, M. W.; GASKELL, G.; ALLUM, N. C. Qualidade, quantidade e interesses do conhecimento. In: BAUER, M. W. Pesquisa qualitativa com texto, imagem e som. Petrópolis: Vozes, 2004.

BAUMAN, Z. Vida para consumo: a transformação das pessoas em mercadoria. Rio de Janeiro: Zahar, 2007.

BORBA, M. A. A brincadeira como experiência de cultura na educação infantil. Revista criança do professor de educação infantil. Brasília: Ministério da Educação, Secretaria de Educação Básica, 2007.

BRANDÃO, E. R.; MORAES, A. Formatos de anúncios veiculados na internet. Apresentação realizada no P\&D Design 2004 - $6^{\circ}$ Congresso Brasileiro de Pesquisa e Desenvolvimento em Design, 2004. Disponível em: http://www.slideshare.net/eduardobrandao/eduardo-brandao-apresentacaocongressopddesign2004\#btnLast. Acesso em: 20 jul. 2013.

CAMPI, M. A vez dos advergames na internet. 3 ago. 2012. Disponível em: http://exame. abril.com.br/marketing/noticias/a-vez-dos-advergames. Acesso em: 30 maio 2013.

CARNIELLO, M.; ASSIS, F. Formatos da publicidade digital: evolução histórica e aprimoramento tecnológico. $7^{\circ}$ Encontro Nacional da ALCAR, 2009. Disponível em: http://www.ufrgs.br/alcar/encontros-nacionais-1/7o-encontro-2009-1/Formatos\%20 da\%20publicidade\%20digital.pdf. Acesso em: 25 jul. 2013.

CRAVEIRO, P. S. U.; \& RIOS, J. R. A. C. Publicidad y juegos digitales en el cotidiano de niños españoles y brasileños: un análisis de la recepción infantil. Estudios sobre el Mensaje Periodístico, v. 19, p. 501-509, 2013.

FONSECA JÚNIOR, W. C. Análise do conteúdo. In: DUARTE, J. \& BARROS, A. Métodos e técnicas de pesquisa em comunicação. São Paulo: Atlas, 2010.

GARMENDiA, M.; GARITAONANDiA, C.; MARTÍNEZ, G.; CASADO, M. A. Riesgos y seguridad en internet: los menores españoles en el contexto europeo. Bilbao: Universidad del País Vasco: EU Kids Online, 2011.

GONZÁLEZ, C.; \& FRANCÉS, M. T. Advergaming aplicado a las estrategias comunicativas dirigidas al target infantil. Actas del Congreso Brand Trends. Valencia: Universidad Cardenal Herrera - CEU, 2009. Disponível em: http://www.uchceu.es/actividades_culturales/2009/congresos/brandtrends/documentos/comunicaciones_textos/ cristina_gonzalez.pdf. Acesso em: 20 maio 2013.

INFOADEX. Estudio Infoadex de la inversión publicitaria en España en 2013. Disponível em: http://www.slideshare.net/FtimaLopez/estudio-infoadex-inversin-publicitaria-2013. Acesso em: 30 maio 2013. 
KAISER FAMILY FOUNDATION. Generation $M^{2}$ : media in the lives of 8 to 18 year olds, 2010. Disponível em: http://kaiserfamilyfoundation.files.wordpress.com/2013/01/8010. pdf. Acesso em: 30 jun. 2012.

MARTÍ PARREÑO, J. Marketing y videojuegos: product placement, in-game advertising y advergaming. Madri: Esic Editorial, 2010.

;; \& CURRÁS PÉREZ, R. Nuevas fórmulas publicitarias: los advergames como herramienta de las comunicaciones de marketing. Cuadernos de Gestión, v. 12, n, 2, p. 43-58, 2012. Disponível em: http://www.ehu.es/cuadernosdegestion/ documentos/100236jm.pdf. Acesso em: 24 maio 2013.

MÉNDIZ NOGUERO, A. Advergaming: concepto, tipología, estrategias y evolución histórica. Revista Icono 14 (en línea), n. 15, 2010. Disponível em: http://www.iconol4. net/Num.-15.-Interactividad/advergaming. Acesso em: 20 maio 2013.

NORDESTE, R. M. Publicidade online das empresas: estratégias actuais. Universidade de Aveiro, Departamento de Comunicação e Artes, 2009. Disponível em: http://ria. ua.pt/bitstream/10773/1178/1/2009001338.pdf. Acesso em: 20 jul. 2013.

PIÑUEL RAIGADA, J. L. Epistemología, metodología y técnicas del análisis de contenido. Estudios de Sociolingüística, v. 3, n.1, p. 1-42, 2002.

PURO MARKETING. El advergaming y la publicidad en videojuegos se expanden rápidamente hacia el medio online. 5 de maio de 2010. Disponível em: http://www. puromarketing.com/72/8112/advergaming-publicidad-videojuegos-expanden-rapidamente-hacia-medio-online.html. Acesso em: 22 maio 2013.

SEBASTIÃO, S. Formatos da publicidade digital: sistematização e desambiguação. Comunicação e Sociedade, v. 19, p. 13-24, 2011. Disponível em: http://www.lasics.uminho. pt/ojs/index.php/comsoc/article/view/894/854. Acesso em: 15 jan. 2013.

TIC KIDS ONLINE 2013. Pesquisa sobre o uso da internet por crianças e adolescentes no Brasil, 2014. Disponível em: http://cetic.br/media/analises/TIC_kids_online_2013_ hangout_imprensa.pdf. Acesso em: $1^{\circ}$ ago. 2014.

TRIVIÑOS, Augusto N. S. Introdução à pesquisa em ciências sociais: a pesquisa qualitativa em educação. São Paulo: Atlas, 1987.

Data de submissão: 01/09/2014

Data de aceite: 15/01/2015 